\title{
COMPARISON OF DISCRETE AND FULL-WAVEFORM ALS FEATURES FOR DEAD WOOD DETECTION
}

\author{
W. Mücke ${ }^{\text {a } *}$, M. Hollaus ${ }^{\text {a }}$, N. Pfeifer ${ }^{\text {a }}$, A. Schroiff ${ }^{b}$ and B. Deák ${ }^{\text {c, d }}$
}

\author{
${ }^{a}$ Dept. of Geodesy and Geoinformation, Vienna University of Technology, Research Group Photogrammetry, \\ Gusshausstraße 27-29, A-1040 Vienna, Austria. (Werner.Muecke, Markus.Hollaus, Norbert.Pfeifer)@geo.tuwien.ac.at \\ ${ }^{\mathrm{b}}$ YGGDRASIL, Diemer Dudenstraße 38, D-10965 Berlin, Germany. ankeschroiff@ yahoo.de \\ ${ }^{c}$ Inst. for Biosciences, Technische Universität Bergakademie Freiberg, Leipziger Str. 29, D-09599 Freiberg, Germany. \\ ${ }^{\mathrm{d}}$ MTA-DE Biodiversity and Ecosystem Services Research Group, Egyetem tér 1., H-4010 Debrecen, Hungary. \\ debalazs@gmail.com
}

KEY WORDS: Forestry, LIDAR, Ecosystem, Inventory, Monitoring

\begin{abstract}
:
The amount of dead wood is a significant parameter for the description and assessment of forest habitat quality under the terms of the Habitats directive and Natura 2000 guidelines. EU member states are obliged by the Natura 2000 regulations to report on habitat quality in a regular interval of six years. To fulfil this task, the areas should be surveyed in the field, which requires an enormous amount of workload if done only by conventional field work. In this study the applicability of airborne laser scanning data as the single data source for the detection of downed trees in forest habitats is investigated. A focus is laid on the comparison of point clouds with only discrete (XYZ) and full-waveform (including echo width) information as input data. In our paper we present an automatic workflow which is able to detect downed trees with high completeness for both data sets $(77.8 \%$ for discrete and $75.6 \%$ for full-waveform data). Due to large amount of false positives, the correctness using discrete ALS data is poorer (63.1\%) than for full-waveform data (89.9\%). It was found that the quality of the result is also influenced by factors such as dimension, state of decay, vegetation density and penetration of the foliage by the laser.
\end{abstract}

\section{INTRODUCTION}

Airborne laser scanning (ALS) is an established method for the estimation of tree height, see, e.g. (Morsdorf et al., 2004). Tree height, however, is only one parameter of interest for characterizing a forest stand. Especially the structure of the vegetation and the non-living elements of the habitats between the canopy surface and the ground surface is of interest in several disciplines. The capability of ALS to record multiple returns, on the one hand, enables characterizing these parameters. The 'returns' (i.e. echoes) from branches, subdominant trees or bushes are used for predicting forest variables (e.g. Hyyppä et al., 2008; Næsset et al., 2004; Reitberger et al., 2009). On the other hand, the development and availability of full-waveform ALS promises to provide even more information on this volume, as - in addition to each point $(\mathrm{x}, \mathrm{y}, \mathrm{z})$ - waveform parameters are recorded for each echo. Fullwaveform data is obtained by digitizing the echo of the transmitted laser pulse, which is caused by the backscatter of the surfaces within the field of view of the laser beam (Wagner et al., 2006).

Methods for exploiting this information provided by the fullwaveform digitization (echo width, cross section, etc.) were described by (e.g. Alexander et al., 2010; Doneus et al., 2008; Heinzel and Koch, 2011; Höfle et al., 2012; Hollaus et al., 2009; Kötz et al., 2006; Mallet and Bretar, 2009; Mücke et al., 2013; Yao et al., 2012). The echo width was interpreted as a measure of vertical distribution of a target, i.e. the surface illuminated by the laser beam, and further on also as a measure of roughness. These interpretations allow assessing the roughness of the investigated surfaces within the laser beam, and thus at the same resolution as the point cloud. In this paper we are testing this hypothesis. The analysis is performed in the context of an application, the detection of dead wood in a forest stand.

The amount of dead wood is a key parameter of biological diversity in forests (e.g. Lassauce et al., 2011). Various groups of animals, fungi and plants are dependent on coarse woody debris (CWD), because it provides nesting habitats, travel corridors and food supply (e.g. Butts and Mccomb, 2000; Riffell et al., 2011). The amount of CWD was found to be positively correlated with essential ecological habitat features of the forests, like resource availability, species richness and naturalness (Christensen et al., 2005). Reporting on the conservation status of those habitats which are involved in the Natura 2000 (N 2000) network (European Commission, 2013) and are listed in the Habitats Directive, is a legally binding requirement for all member states of the European Union (EU). The assessment and reporting schemes, which have to be fulfilled in cycles of six years, also include information on amounts of dead wood within a specific area.

As manual quantification of CWD through conventional field survey in forested N 2000 sites is a resource-consuming task, recent research was dedicated to supporting the assessment process with methods of remote sensing. Especially the application of airborne laser scanning has a high potential for this task, as it is able to provide a 3D depiction of the forest vegetation, from the canopy down to the ground. Vehmas et al. (2011) used an ALS-based canopy height model for the detection of canopy gaps. They were able to correlate the amount of CWD with ALS-based height and distribution metrics. Bater et al. (2009) employed a set of ALS predictor

\footnotetext{
* Corresponding author.
} 
variables (e.g. height density metrics, mean, maximum, standard deviation, etc.) in a statistical regression-based approach in order to predict cumulative amounts of standing dead trees on plot level. Kim et al. (2009) found the ALS echo intensity and computed canopy volume estimates to be suitable indicators for determination of live biomass. Their results however indicated that the estimation of dead biomass was significantly more challenging. Pesonen et al. (2008) also derived ALS height and intensity-based metrics, and similarly they used regression models for the prediction of standing and downed dead wood volumes.

All afore mentioned publications rely on statistical approaches for the correlation of ALS-based metrics and field-based estimates of CWD. To this day and the author's best knowledge, only two studies exist investigating ALS data as a basis for direct mapping of CWD. Firstly, Blanchard et al. (2011) applied object-based image analysis for the mapping of downed logs in an area after a severe storm, which did (no longer) feature any shrub vegetation or remaining overgrowing trees. They documented classification success of $73 \%$ based on gridded ALS metrics, when compared to manually digitized logs. Secondly, Yao et al. (2012) used the single tree segmentation method proposed by Reitberger et al. (2009), and derived geometric and radiometric features for discriminating standing dead and live trees on single tree level. For their high-density ALS data ( $>25$ echoes $/ \mathrm{m}^{2}$ ) they achieved an accuracy of $73 \%$. In this contribution we are comparing discrete and fullwaveform information as input for detection method. "Discrete" information refers to discrete return laser scanning, however only one data set is used for the entire analysis. This data set was generated with a full-waveform digitizing laser scanner. It is thus not investigated if there is a benefit in using the higher number of echoes provided by full waveform laser scanning, as referred to in (e.g. Reitberger et al., 2009), but if the echo width provides an additional beneficial measure, which is not available in the entire cloud of $(\mathrm{x}, \mathrm{y}, \mathrm{z})$ points.

In Sec. 2 the study site is presented, in Sec. 3 the methods are described, and the results are discussed in Sec. 4.

\section{STUDY AREA AND DATA}

\subsection{Study area}

The study site (Figure 1) is situated in the DebrecenHajdúböszörményi tölgyesek’ N 2000 site (Eastern-Hungary). It is dominated by pedunculate oak (Quercus robur), field maple (Acer campestre), wild cherry (Cerasus avium) and linden species (Tilia spp.).



Figure 1: nDSM of Natura 2000 study site (red borderline) in Eastern Hungary.

The habitat is multi-layered: it has two distinct canopy layers, a dense shrub and a species-rich herb layer. No forestry management is practiced and significant amount of CWD were encountered during field surveys.

\subsection{Data}

2.2.1 Field data: During leaf-on and leaf-off season in 2012 and 2013 several field campaigns were conducted in the study site for the purpose of $\mathrm{N} 2000$ habitat mapping and assessment. The start- and endpoints of encountered downed stems with a diameter bigger than $0.3 \mathrm{~m}$ (a standard in N 2000 mapping) were measured using a geodetic-grade differential GNSS (dGNSS) receiver (documented accuracies were less than $0.1 \mathrm{~m}$ ). The exact diameter and length of each downed stem was measured and noted. Tree stumps and piles of twigs (fine woody debris, FWD) were mapped with one dGNSS point in their centre. Photographs of every measured point were taken and stored together with the cardinal direction of the image acquisition. In total, 86 objects (CWD and FWD) were mapped in the study site.

2.2.2 Airborne laser scanning data: A RIEGL LMS Q-680i full-waveform laser scanner (RIEGL, 2013a) mounted on a fixed wing aircraft was used for data acquisition, which was conducted in March 2012 (leaf-off). A minimum strip overlap of $50 \%$, a deflection angle of $+/-30^{\circ}$, pulse repetition rate of $400 \mathrm{kHz}$ and mean altitude of $500 \mathrm{~m}$ a.g.l. resulted in an average of 29.4 echoes $/ \mathrm{m}^{2}$ (considering all echoes) or 10.9 echoes $/ \mathrm{m}^{2}$ (considering only single or last echoes). The diameter of the footprint at the given altitude corresponded roughly to $0.25 \mathrm{~m}$. Waveform processing of the raw data was done with Gaussian decomposition (Wagner et al., 2006), which is implemented in the software RiProcess (RIEGL, 2013b).

Hierarchic robust filtering as described by Pfeifer et al. (2001) was applied to create a $0.25 \times 0.25 \mathrm{~m}^{2}$ digital terrain model (DTM) based on the last echoes. The point cloud was then augmented with normalized heights (i.e. echo heights relative to DTM). The final point cloud contained nine features per point: 3D coordinates (east, north, ellipsoidal height), GPS time, echo amplitude, echo width, echo number, total number of echoes per emitted pulse, and normalized height.

\section{METHODS}

\subsection{Concept of downed stem detection}

The basic idea behind the stepwise detection process is to create a digital height model (DHM) which includes the downed stems and from which the stems can afterwards be extracted. For this purpose all the echoes from vital vegetation possibly covering or overgrowing the fallen trees need to be excluded in order to expose them. The hypothesis is that vegetation can be distinguised from the forest ground by more inhomogeneous surface characteristics (i.e. increased surface roughness). Following the concept proposed by Hollaus et al. (2011) roughness can be described in multiple scales using ALS data. Firstly, high-density small-footprint ALS point clouds, like the one we used for this study, represent surface roughness through the distribution of the echoes. Normalized heights of neighbouring echoes will be more divergent in vegetated areas than on bare ground. Given adequate penetration of the foliage, this characteristic can be exploited for discrimination of ground and low vegetation (e.g. Vetter et al., 2011) (c.f. Sec. 3.3). Secondly, full-waveform ALS data additionally provides the width of the reflected pulse (i.e. echo width), which relates to small height variations of scattering elements within the footprint of the laser beam (Wagner et al., 2008). Essentially 
this means that the echo width tends to widen up compared to the emitted laser pulse if it is reflected from a more inhomogeneous (i.e. rough) surface. It can therefore be understood as a measure of sub-footprint roughness (c.f. Sec. $3.2)$.

\subsection{Roughness features derived from full-waveform data}

The echo width is available for every echo as a result of the Gaussian decomposition. It does not need any further processing and can be used instantly as a selector for the single echo. As the echo width always relates to a specific ALS point, the roughness information derived from it will further be referred to as "point-based roughness".

Explorative data analysis carried out for this study has shown that a threshold of $4.75 \mathrm{~ns}$ applied on the point cloud managed to largely, but not entirely, exclude large parts of the shrub and herbaceous vegetation in the study area.

Apart from the single echo threshold, the echo width was also used to derive a $1 \times 1 \mathrm{~m}^{2}$ grid model of the echo width variance. This grid model describes the divergence of neighbouring echoes, and according to the afore described hypothesis, should show larger variations in areas covered by low vegetation. It is also meant to further determine objects not representing downed stems, which were not eliminated in the first step with the echo width threshold. This measure of surface roughness is dependent on the distribution of neighbouring echoes and their attributes, thus it is further referred to as "distribution-based roughness".

Both features were created based on echoes within a range of $0.1 \mathrm{~m}$ and $2 \mathrm{~m}$ normalized height. These thresholds were on the one hand motivated by the ranging accuracy of the laser scanner and definition uncertainty of the forest ground $(0.1 \mathrm{~m})$, and on the other hand by the fact that the biggest uprooted stems and their vertical root plates did not exceed a height of $2 \mathrm{~m}$ in most cases.

\subsection{Roughness features derived from discrete data}

In contrast to full-waveform data, discrete data do not provide roughness information "out-of-the-box" for every echo; it needs to be generated in further processing steps (like the echo width variance grid model). Such features are based on the relations of neighbouring echoes, and therefore all of the following roughness features are referred to as "distribution-based".

For this study OPALS (Orientation and Processing of Airborne Laser Scanning data), which is a scientific software project developed at the Vienna University of Technology (Mandlburger et al., 2009), was used for ALS data processing. OPALS is a modular software system, consisting of several small modules. Each module covers a well defined task (e.g. data management, raster operations, grid operations, point operations) and is available as command-line executable, Python module (Phyton, 2012), and C++ class library via DLL linkage. Further details can be found at the OPALS website (OPALS, 2013).

The required distribution-based roughness calculations based on the 3D point neighbourhood were carried out using the module opalsPointStats. This module allows the derivation of statistical parameters describing the distribution of point attributes (e.g. height, echo width, amplitude) within a local, circular neighbourhood. The neighbourhood for point selection can be defined in 2D (cylinder) or 3D (sphere). The selected statistical features are calculated based on the attribute deviations from a reference model. This reference model can either be represented by a horizontal or tilted plane, or a grid file (e.g. DTM, DSM). For this study we calculated the root mean square (RMS), variance, range, and median of the last echoes between $0.1 \mathrm{~m}$ and $2 \mathrm{~m}$ normalized height with respect to a horizontal and tilted plane. The reference height of the horizontal plane is defined by the height of the current feature point, whereas the tilted plane is represent by the local surface tangent plane passing through the current feature point.

The derived statistical parameters were added as an additional attribute to the corresponding point (but still describe the neighbourhood). For further processing these derived additional attributes were gridded using the opalsCell module, resulting in raster models as input for the classification task in the last step of the workflow. This step assigned roughness values to single objects and is thus referred to as "object-based roughness" assignment.

\subsection{Overview of the workflow}

The workflow (Figure 2) starts with applying the normalized height and, in case of full-waveform data, echo width thresholds on the $3 \mathrm{D}$ point cloud. For the discrete data set only the normalized height threshold is used in this step. Based on the resulting filtered point cloud a DHM is created by moving least squares interpolation. This DHM clearly shows the possible locations of downed stems (referred to as stem candidates) as elongated features (Figure 3a), thus it is called DHM cand $_{\text {(grid }}$ size $0.25 \times 0.25 \mathrm{~m}^{2}$ ). Afterwards, the difference model of DTM and $\mathrm{DHM}_{\text {cand }}$, so-called normalized $\mathrm{DHM}_{\text {cand }}\left(\mathrm{nDHM}_{\text {cand }}=\right.$ $\mathrm{DHM}_{\text {cand }}$ - DTM) is calculated, on which a height threshold of $0.1 \mathrm{~m}$ is applied to separate downed stems as non-terrain features. The resulting model is binary classified ( 1 if $\mathrm{nDHM}_{\text {cand }}$ $>0.1 \mathrm{~m}$, else 0 ) and morphological closing is carried out. This step ensures that stem parts separated by the height threshold are re-connected and the closing also fills holes. The final binary image shows elongated areas presumably representing downed wood and spot-like features which are assumed to represent stems of standing trees or still remaining low vegetation. The image is converted to a vector format (ESRI shape), thus creating one polygon outline for every connected region. An area-perimeter-ratio $\left(a p_{\text {ratio }}\right)$ is computed as follows

$$
a p_{\text {ratio }}=4 * p * a / p^{2}
$$

where $a$ is the area and $p$ is the perimeter of a respective polygon. This value is close to one for circle-like polygons and becomes smaller the more elongated a polygon is. To eliminate the afore mentioned spot-like areas that presumably represent stems of standing trees, empirically derived thresholds of $a p_{\text {ratio }}$ $>=0.3$ and $\mathrm{a}<4 \mathrm{~m}^{2}$ are applied and the respective polygons are omitted.

In the last step, the derived grid models representing distribution-based roughness features (cf. Sec. 3.2 and 3.3) are intersected with the outlines of the stem candidates to assign object-based roughness values for every outline. This final step is intended to identify well-detectable stems (featuring low surface roughness) from the rest, which are possible stem candidates but due to their surface roughness cannot be clearly identified as such (because they are heavily overgrown).

Two outline maps are created as a final result: one holding the result from the full-waveform data (Figure $3 b$ yellow polygons), and the other from the discrete data (Figure $3 \mathrm{~b}$ green polygons). 


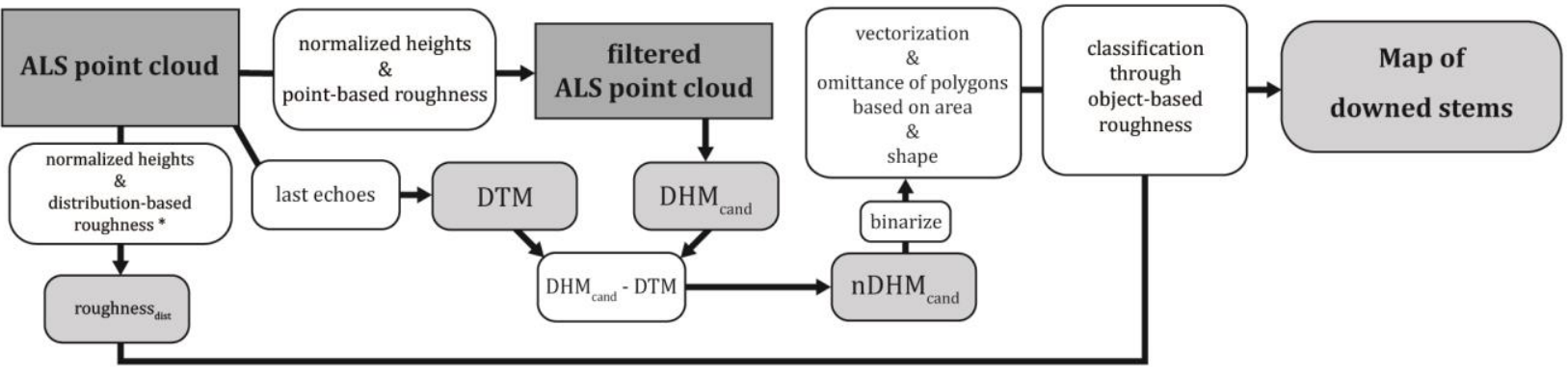

Figure 2: Schematic depiction of the workflow for the detection of the downed stems. * distribution-based roughness features are either created from the full-waveform attribute echo width or 3D echo distribution features solely from discrete information (e.g. variance of normalized heights, RMS of normalized heights with respect to local horizontal plane, etc.) (modified from Mücke et al., 2013).

\subsection{Validation}

Visual comparison revealed position offsets of the reference data set and the detected downed stems of $0.5 \mathrm{~m}$ to $3 \mathrm{~m}$. At this point it can only be assumed that shadowing effects, bad satellite constellations, or other accuracy diminishing effects during the GNSS observations in the field (e.g. multipath effects) were responsible for this situation, which made direct automated comparison of both data sets (reference and classification results) and consequently automated accuracy assessment impossible. Nevertheless, each field-measured downed stem could be visually assigned to a corresponding one in the result if it was (1) in close proximity, and (2) similar in length and direction. Therefore, manual accuracy assessment was carried out based on the following rules: the stem was marked as

- "found" if the lengthwise agreement of ALS-based outline and assigned reference $\geq 75 \%$

- "partly found" if the lengthwise agreement of ALSbased outline and assigned reference was $<75 \%$

- "not found" if no reference could be assigned.

Afterwards, a performance evaluation was conducted calculating completeness (i.e. Producer's accuracy) and correctness (i.e. User's accuracy) as follows (Heipke et al., 1997):

$$
\begin{gathered}
\text { Completeness }=\|\mathrm{TP}\| /\|\mathrm{TP}\|+\|\mathrm{FN}\| \\
\text { Correctness }=\|\mathrm{TP}\| /\|\mathrm{TP}\|+\|\mathrm{FP}\|
\end{gathered}
$$

where a True Positive (TP) is a stem that is included in the ALS-based outlines and is also in the reference data. A False Positive (FP) is a stem that is included in the ALS-based outlines but is not in the reference data. A stem that is not found by the detection process but is present in the reference data is called a False Negative (FN).

\section{RESULTS AND DISCUSSION}

Figure $3 b$ shows the result of the classification process. The outlines generated by discrete ALS data are displayed in green, the outlines from full-waveform data in yellow. Visual comparison of the results indicates that both sets of outlines show similar completeness. However, obviously the outlines based on the discrete input data include significantly more FPs. The quality assessment supports this impression, as it determined a completeness of $75.6 \%$ and correctness of $89.9 \%$ for full-waveform data. In contrast, the discrete data produced a completeness of $77.8 \%$ and correctness of $63.1 \%$ (Error!

\begin{tabular}{|c|c|c|c|c|c|}
\hline \multirow{2}{*}{\begin{tabular}{|l} 
Input data \\
Full-waveform
\end{tabular}} & \multicolumn{3}{|c|}{$\begin{array}{lll}\mathbf{T P} & \mathbf{F P} & \mathbf{F N} \\
& {[\#]} & \\
& \end{array}$} & \multicolumn{2}{|c|}{$\begin{array}{c}\text { Comp. Corr. } \\
{[\%]}\end{array}$} \\
\hline & 62 & 7 & 20 & 75.6 & 89.9 \\
\hline Discrete & 70 & 41 & 20 & 77.8 & 63.1 \\
\hline
\end{tabular}
Reference source not found.).
Table 1: Results of the validation. Comparison of fullwaveform and discrete data input.

The combined normalized height and echo width filters applied in the first step of the workflow were able to eliminate a large amount of shrub and herbaceous vegetation areas. Remaining spot-like areas representing stems of vital trees or remaining low vegetation were omitted by the combined shape and roughness criterion in the last classification step, using the distribution-based echo width variance raster model.

In contrast, the same separation of ground, stems and low vegetation could not be achieved with the discrete ALS data. Starting with the first step of the detection process more echoes representing low vegetation areas remained in the point set and, thus, in the initial vectorized outlines. Although a slightly more complete result could be achieved, the correctness in contrast suffered due to the high amount of FPs. None of the calculated distribution-based roughness features was able to clearly discriminate between a downed stem and vegetation outline. Visual comparison with the terrestrial photographs showed that most of the stems that were only partly or not found were highly decayed (Figure 4c).

The quality of the result was also highly dependent on the underlying DTM. A rigorous filtering of terrain and non-terrain points had to be chosen because the initial echo selection was based on normalized heights. Again, stems that did not distinguish themselves clearly from the forest ground were included in the DTM and remained undetectable. On the other hand, line-like topographic features (e.g. ditches along a forest path) were sometimes smoothed by the DTM generation process. This resulted in polygons with similar characteristics as the downed stems (smooth, often bigger than $4 \mathrm{~m}^{2}$, line-like) which could not be excluded from the final result. They could be distinguished neither by full-waveform nor by discrete ALS data and remained as FPs.

The approach presented by Blanchard et al. (2011) achieved comparably classification quality (73\%). However, they applied their method on mostly open area (only small parts were covered by standing trees) and they stated that misclassification happened in areas with clusters of downed logs and lower vegetation. Undoubtedly, the analysis of such a difficult area is a strength of full-waveform data, if available, and of the method presented in this study. 


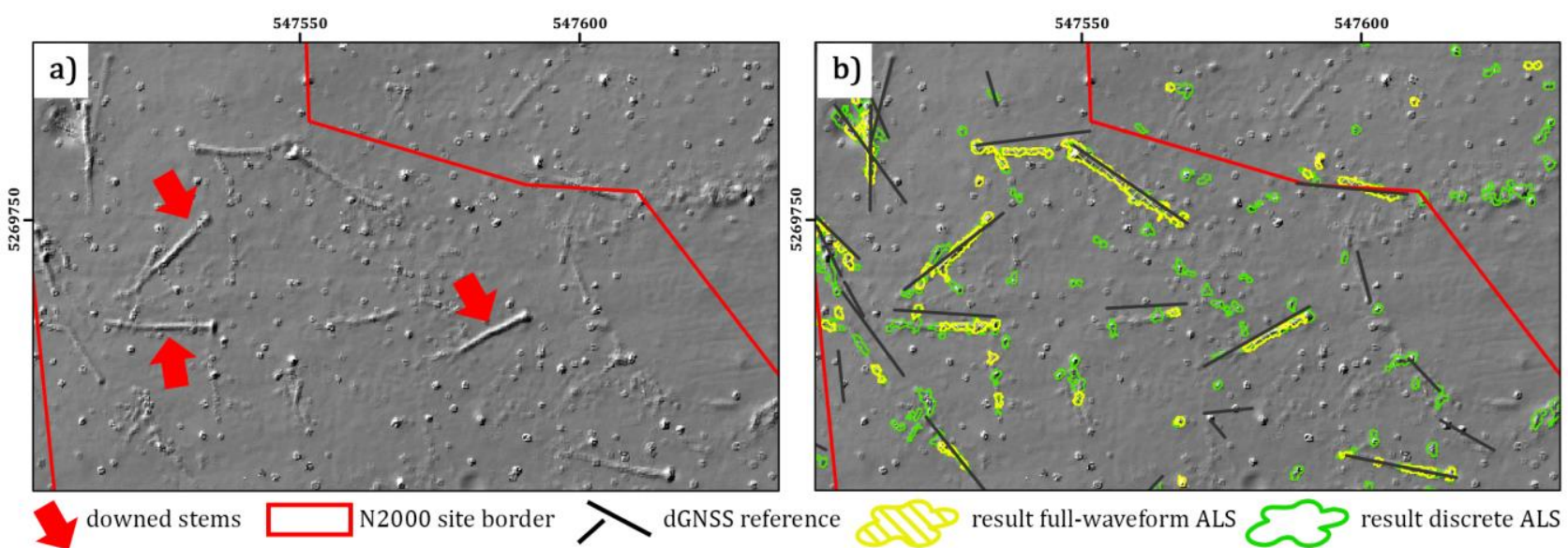

Figure 3: (a) shading of the $\mathrm{DHM}_{\text {cand }}$ showing downed stems in the study site (some examples marked by red arrows);

(b) comparison of results from discrete and full-waveform input data. Black lines represent dGNSS reference measurements of stems.
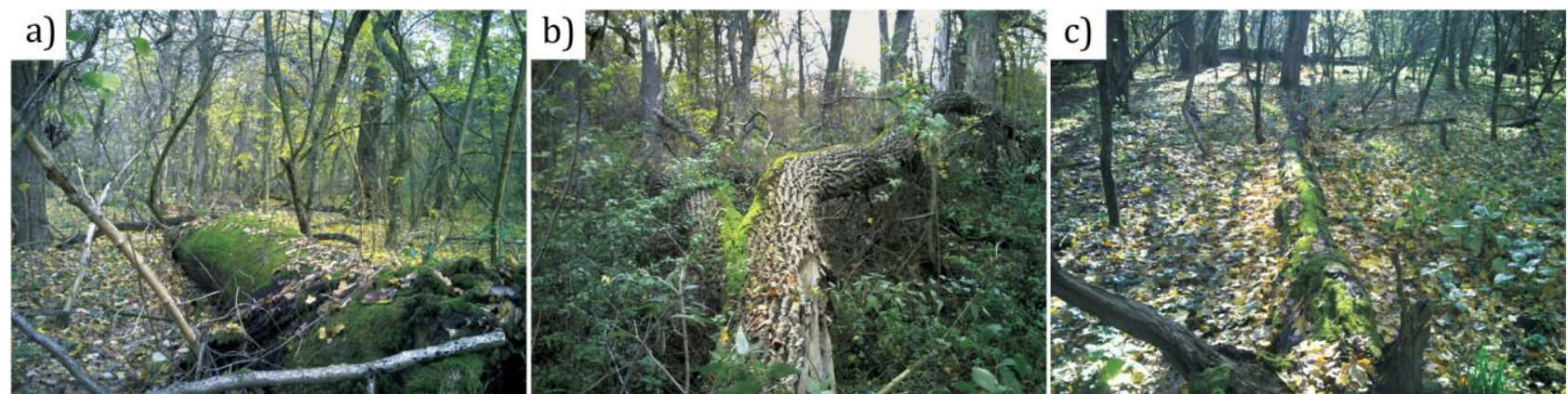

Figure 4: Examples of detected downed stems in the study site (a,b), and an example for an un-detected stem due to high degree of decay and small diameter (c).

\section{CONCLUSION}

Comparison of discrete and full-waveform data for application in forestry and nature conservation related questions is a wellfounded task. To this day, full-waveform ALS remains a novel technique, its potentials being far from exploited. Most often only the 3D information is used and the additional information content being omitted. With this study we compared the ability of both, discrete and full-waveform data, for dead wood detection. We found and demonstrated that the echo width is an irreplaceable and adequate parameter for the identification of echoes from low vegetation and the parameterization of subfootprint surface roughness. With respect to the footprint size of the ALS data available for this study, the surfaces of the downed stems appeared smooth in relation to the shrub or herbaceous layers, which could be identified by the magnitudes of the echo widths of respective echoes from these objects.

A workflow for the detection of downed stems was presented. Elongated, thick (diameter $>0.5 \mathrm{~m}$ ) and well-preserved stems were found reliably, regardless of possible coverage by low vital vegetation or FWD (Figure $4 \mathrm{a}$ and $\mathrm{b}$ ). More decayed stems or smaller diameters resulted in less distinct outlines and were less likely to be found by the automatic detection.

The results of the proposed method enable ecologists to gain an overview on the state of habitats. It can be used to evaluate the effects of severe natural disasters (e.g. storms, landslides, etc.). Multi-temporal data at hand it can highlight areas were significant changes happened over time (potential biodiversity hot spots), which in turn opens up the opportunity for precise long term monitoring of ecological processes. A focus can subsequently be laid on these areas, thus making the whole assessment process more economically efficient.

\section{ACKNOWLEDGEMENTS}

This study was partly funded by the "NEWFOR" project financed by the European Territorial Cooperation "Alpine Space" and the "ChangeHabitats2" project (Marie Curie -FP7 PEOPLE-2009-IAPP - Grant Agreement Number 251234). We would also like to extend our gratitude to RIEGL Laser Measurements $\mathrm{GmbH}$ for kindly providing the ALS data. Additionally we wish to thank Professor Hermann Heilmeier for his constructive feedback on the manuscript.

\section{REFERENCES}

Alexander, C., Tansey, K., Kaduka, J., Holland, D. and Tate, N.J., 2010. Backscatter coefficient as an attribute for the classification of full-waveform airborne laser scanning data in urban areas. ISPRS Journal of Photogrammetry and Remote Sensing 65 (5), 423-432.

Bater, C.W., Coops, N.C., Gergel, S.E., Lemay, V.L. and Collins, D., 2009. Estimation of standing dead tree class distributions in northwest coastal forests using lidar remote sensing. Canadian Journal of Forest Research 39 (6), 10801091.

Blanchard, S.D., Jakubowski, M.K. and Kelly, M., 2011. Object-based image analysis of downed logs in disturbed forested landscapes using lidar. Remote Sensing 3 (11), 24202439.

Butts, S.R. and McComb, W.C., 2000. Associations of forestfloor vertebrates with coarse woody debris in managed forests 
of western Oregon. The Journal of wildlife management 64 (1), 95-104.

Christensen, M., Hahn, K., Mountford, E.P., Ódor, P., Standovár, T., Rozenbergar, D., Diaci, J., Wijdeven, S., Meyer, P. and Winter, S., 2005. Dead wood in European beech (Fagus sylvatica) forest reserves. Forest Ecology and Management 210 (1), 267-282.

Doneus, M., Briese, C., Fera, M. and Janner, M., 2008. Archaeological prospection of forested areas using fullwaveform airborne laser scanning. Journal of Archaeological Science 35 (4), 882-893.

European Commission, 2013. European environment agency's home page - european environment agency (EEA). The Habitats directive.

http://ec.europa.eu/environment/nature/legislation/habitatsdirect ive/index_en.htm. Last accessed June 2013.

Heinzel, J. and Koch, B., 2011. Exploring full-waveform LiDAR parameters for tree species classification. International Journal of Applied Earth Observations and Geoinformation 13 (1), 153-160.

Heipke, C., Mayer, H., Wiedemann, C. and Jamet, O., 1997. Evaluation of automatic road extraction. International Archives of Photogrammetry and Remote Sensing 32 (3 SECT 4W2), 151-160.

Höfle, B., Hollaus, M. and Hagenauer, J., 2012. Urban vegetation detection using radiometrically calibrated smallfootprint full-waveform airborne LiDAR data. ISPRS Journal of Photogrammetry and Remote Sensing 67 (1), 134-147.

Hollaus, M., Aubrecht, C., Höfle, B., Steinnocher, K. and Wagner, W., 2011. Roughness Mapping on Various Vertical Scales Based on Full-Waveform Airborne Laser Scanning Data. Remote Sensing 3 (3), 503-523.

Hollaus, M., Mücke, W., Höfle, B., Dorigo, W., Pfeifer, N., Wagner, W., Bauerhansl, C. and Regner, B., 2009. Tree species classification based on full-waveform airborne laser scanning data. 9th International Silvilaser Conference, October 14-16, 2009 - Texas A\&M University, College Station, TX, USA, 5462.

Hyyppä, J., Hyyppä, H., Leckie, D., Gougeon, F., Yu, X. and Maltamo, M., 2008. Review of methods of small-footprint airborne laser scanning for extracting forest inventory data in boreal forests. International Journal of Remote Sensing 29 (5), 1339-1366.

Kim, Y., Yang, Z., Cohen, W.B., Pflugmacher, D., Lauver, C.L. and Vankat, J.L., 2009. Distinguishing between live and dead standing tree biomass on the north rim of grand canyon national park, USA using small-footprint lidar data. Remote sensing of environment 113 (11), 2499-2510.

Kötz, B., Morsdorf, F., Sun, G., Ranson, K.J., Itten, K. and Allgöwer, B., 2006. Inversion of a lidar waveform model for forest biophysical parameter estimation. IEEE Geoscience and Remote Sensing Letters 3 (1), 49-53.

Lassauce, A., Paillet, Y., Jactel, H. and Bouget, C., 2011. Deadwood as a surrogate for forest biodiversity: meta-analysis of correlations between deadwood volume and species richness of saproxylic organisms. Ecological Indicators 11 (5), 10271039.

Mallet, C. and Bretar, F., 2009. Full-waveform topographic lidar: State-of-the-art. ISPRS Journal of Photogrammetry and Remote Sensing 64 (1), 1-16.

Mandlburger, G., Otepka, J., Karel, W., Wagner, W. and Pfeifer, N., 2009. Orientation And Processing Of Airborne Laser Scanning Data (opals) - Concept And First Results Of A Comprehensive Als Software. In: (Eds.): ISPRS Workshop Laserscanning '09, IAPRS, Vol. XXXVIII, Part 3/W8, Paris, $55-60$.
Morsdorf, F., Meier, E., Kötz, B., Itten, K.I., Dobbertin, M. and Allgöwer, B., 2004. LIDAR-based geometric reconstruction of boreal type forest stands at single tree level for forest and wildland fire management. Remote Sensing of Environment 92 (2), 353-362.

Mücke, W., Deák, B., Schroiff, A., Hollaus, M. and Pfeifer, N., 2013. Detection of fallen trees in forested areas using small footprint airborne laser scanning data. Canadian Journal of Remote Sensing 39 (S1), S1-S9.

Næsset, E., Gobakken, T., Holmgren, J., Hyyppä, H., Hyyppä, J., Maltamo, M., Nilsson, M., Olsson, H., Persson, A. and Söderman, U., 2004. Laser scanning of forest resources: the Nordic experience. Scandinavian Journal of Forest Research 19 (6), 482-499.

OPALS, 2013. OPALS - Orientation and Processing of Airborne Laser Scanning Data, http://geo.tuwien.ac.at/opals/. Last accessed June 2013.

Pesonen, A., Maltamo, M., Eerikäinen, K. and Packalén, P., 2008. Airborne laser scanning-based prediction of coarse woody debris volumes in a conservation area. Forest Ecology and Management 255 (8), 3288-3296.

Pfeifer, N., Stadler, P. and Briese, C., 2001. Derivation of Digital Terrain Models in the SCOP++ Environment. In: (Eds.): OEEPE Workshop on Airborne Laserscanning and Interferometric SAR for Detailed Digital Elevation Models, 1.3. March 2001, Stockholm, Sweden, 13 pp.

Phyton, 2012. Python Programming Language, http://www.python.org/. Last accessed June 2012.

Reitberger, J., Schnörr, C., Krzystek, P. and Stilla, U., 2009. 3d segmentation of single trees exploiting fullwaveformlidar data. ISPRS Journal of Photogrammetry andRemote Sensing 64 (6), 561-574.

RIEGL, 2013a. RIEGL LMS Q680i.

http://www.riegl.com/nc/products/airborne-scanning/ produktdetail/product/scanner/23/. Last accessed June 2013.

RIEGL, 2013b. Riegl riprocess. http://www.riegl.com/products/ software-packages/riprocess/. Last accessed June 2013.

Riffell, S., Verschuyl, J., Miller, D. and Wigley, T.B., 2011. Biofuel harvests, coarse woody debris, and biodiversity a metaanalysis. Forest Ecology and Management 261 (4), 878-887.

Vehmas, M., Packalén, P., Maltamo, M. and Eerikäinen, K., 2011. Using airborne laser scanning data for detecting canopy gaps and their understory type in mature boreal forest. Annals of Forest Science 68 (4), 825-835.

Vetter, M., Höfle, B., Hollaus, M., Gschöpf, C., Mandlburger, G., Pfeifer, N. and Wagner, W., 2011. Vertical vegetation structure analysis and hydraulic roughness determination using dense ALS point cloud data - a voxel based approach, ISPRS Workshop Laser Scanning 2011, Calgary, Canada; 2011-08-29 - 2011-08-31, pp. 6.

Wagner, W., Hollaus, M., Briese, C. and Ducic, V., 2008. 3D vegetation mapping using small-footprint full-waveform airborne laser scanners. International Journal of Remote Sensing 29 (5), 1433-1452.

Wagner, W., Ullrich, A., Ducic, V., Melzer, T. and Studnicka, N., 2006. Gaussian decomposition and calibration of a novel small-footprint full-waveform digitising airborne laser scanner. ISPRS Journal of Photogrammetry \& Remote Sensing 60 (2), 100-112.

Yao, W., Krzystek, P. and Heurich, M., 2012. Identifying standing dead trees in forest areas based on 3D single tree detection from full waveform LiDAR data. ISPRS Annals of the Photogrammetry, Remote Sensing and spatial information Sciences 1-7, pp. 6 . 